\title{
Ergonomic Knob Design Validation for Improved Musculoskeletal Comfort
}

\author{
Poh Kiat Ng${ }^{1}$, Yue Hang Tan ${ }^{1}$, Kian Siong Jee ${ }^{1}$, Li Wah Thong ${ }^{1}$, Jian Ai Yeow ${ }^{2}$ \& Chiew Yean $\mathrm{Ng}^{3}$ \\ ${ }^{1}$ Faculty of Engineering and Technology, Multimedia University, Malacca, Malaysia \\ ${ }^{2}$ Faculty of Business, Multimedia University, Malacca, Malaysia \\ ${ }^{3}$ Department of Radiology, Columbia Asia Hospital, Puchong, Selangor, Malaysia \\ Correspondence: Poh Kiat Ng, Faculty of Engineering and Technology, Multimedia University, Jalan Ayer Keroh \\ Lama, Bukit Beruang, 75450 Malacca, Malaysia. E-mail: pkng@mmu.edu.my
}

Received: September 16, 2015 Accepted: September 29, $2015 \quad$ Online Published: December 21, 2015

doi:10.5539/mas.v10n1p76 URL: http://dx.doi.org/10.5539/mas.v10n1p76

The research is financed by the Ministry of Education Malaysia through the Fundamental Research Grant Scheme (Ref No.: MMU/RMC-PL/AL/FRGS/2013/006).

\begin{abstract}
Ergonomic control devices can minimise risks of hand-related injuries. The pinch force exerted on a control knob during operations can be minimised so that excessive physical stress and strain on the hands are reduced. This improves working performance. Studies indicate that milling machine control knobs are difficult to operate. Hence, this study aims to validate an ergonomic knob design against a milling machine knob design to determine the extent of musculoskeletal comfort improvement. An ergonomic knob is designed based on a knurled spherical knob with ergonomics features. A validation is performed by requesting 12 participants to turn the knobs in clockwise and counterclockwise directions. Pinch force data is recorded. Findings show that the ergonomic knob reduces more than $55 \%$ of pinch force compared to the milling machine knob replica. This study is useful for machine designers in the development of safer and more ergonomic knobs for various equipment, apparatus and devices.
\end{abstract}

Keywords: knob design, validation, ergonomics, knob shape, musculoskeletal comfort

\section{Introduction}

The productivity and performance of workers can be affected with excessive physical stress and strain, and this can lead to muscle fatigue and injuries (Schutte \& Schuder, 1997). Researchers believe that with proper ergonomics design considerations of work tasks and control interfaces, the risk of hand-related injuries can be minimised (Eksioglu, Fernandez, \& Twomey, 1996). Therefore, the design of controls should not only be made in accordance to specifications, but also should be based on ergonomics design considerations (Schutte \& Schuder, 1997).

Stevenson, Coleman, Long and Williamson (2000) found that spherical knobs allow the execution of a more natural wrist position when they are operated and are also more preferred by users. The size and shape of a knob are also found to be an important factor in ergonomics design considerations, especially when high force is required to operate the knob (Kleiss, 2008; Woodson, Tillman, \& Tillman, 1992).

It has also been found that pinch width can greatly affect the amount of force exerted by a person (Campbell, Nolan, Wharton, \& Train, 2000). Apart from that, Fathallah, Kroemer and Waldron (1991) also found that the optimum pinch width which can help to generate the maximum pinch force is at about $5 \mathrm{~cm}$.

Prior to this study, a new knob was designed based on ergonomics design considerations (Ng \& Saptari, 2014; $\mathrm{Ng}$, Saptari, Boon, Bee, Chai,\& Leh, 2014b). The ergonomics design considerations adopted for the creation of the knob included factors such as the shape of the knob, clockwise and counterclockwise torque direction, increased and reduced tactile sensation, body posture, arm posture and finger position (Tan, Ng, Saptari,\& Jee, 2014; Tan, Ng, Saptari, \& Jee, 2015a; Tan, Ng, Saptari,\& Jee, 2015b). However, in order to determine if the knob does indeed improve musculoskeletal comfort, a validation of its ability to reduce pinch force is required. 
Hence, the aim of this study is to validate the ergonomic knob design against a milling machine knob design to determine the extent of musculoskeletal comfort improvement.

\section{Milling Machine Knob Replica}

Some machine control knobs are difficult to be rotated and this may lead to the inefficiency of work done and even musculoskeletal disorders. In this study, the gear changing control knobs on a milling machine are found to be particularly difficult for manipulation. Hence, a new design with ergonomics design considerations is made to solve this problem. In order to validate this new design, a replica of the milling machine knob is fabricated. The knurling and diameter of the knob are reproduced to resemble those of the actual control knob on the milling machine. Figure 1 shows the actual milling machine control knob and the milling machine knob replica.



(a)

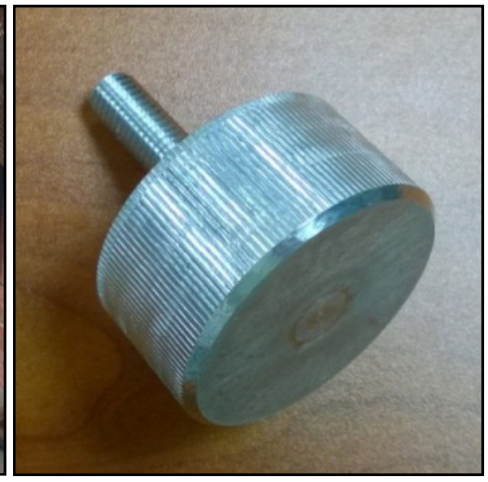

(b)

Figure 1. (a) Actual Control Knob on the Milling Machine (b) Milling Machine Knob Replica

\section{Ergonomic Knob Design}

The ergonomic knob design used in this study is based on a knurled spherical knob, which has been identified as the most commonly and preferably used type of knob among manual workers in manufacturing industries according to surveys and observational studies prior to this study (Tan et al., 2015a).

Grooves are added to the ergonomic knob to support its turning in a counterclockwise direction, as this direction is found to cause more difficulty in force exertion compared to the clockwise direction (Seo, Armstrong, Chaffin, \& Ashton-Miller, 2008). Since the lateral pinch has been identified as the most efficient pinch grip based on experiments prior to this research (Ng, Bee, Boon, Chai, Leh, \& Jee, 2014a; Ng et al., 2014b), the grooves are specifically designed to accommodate the thumb and index finger (lateral pinch uses the thumb and lateral aspect of index finger). The width of the grooves are also designed to fit the majority of the finger sizes of Asian people based on the anthropometric measurements obtained from previous studies (Chakrabarti, 1997; Deros, Yusuff, Daruis, Mohamad, \& Yusoff, 2013; Karmegam, Sapuan, Ismail, Ismail, Bahri, Shuib, Mohana, Seetha, TamilMoli, \& Hanapi, 2011; Ran, Zhang, Chao, Liu, \& Dong, 2009).

Rubbery materials are added on the groove surface to enhance frictional force. It has been found in previous research that higher frictional force is better for the user when turning the knob, especially for strong and extended periods of force application (Seo, Shim, Engel, \& Enders, 2011). Engel, Enders, Keenan and Seo(2010) also suggested that people would be able to exert higher pinch forces when gripping on a knob with a higher surface friction. The overall diameter of the ergonomic knob is made to accommodate the optimum pinch width, which is about $50 \mathrm{~mm}$ (Fathallah et al., 1991). Figure 2 shows the actual product of the ergonomic knob. 


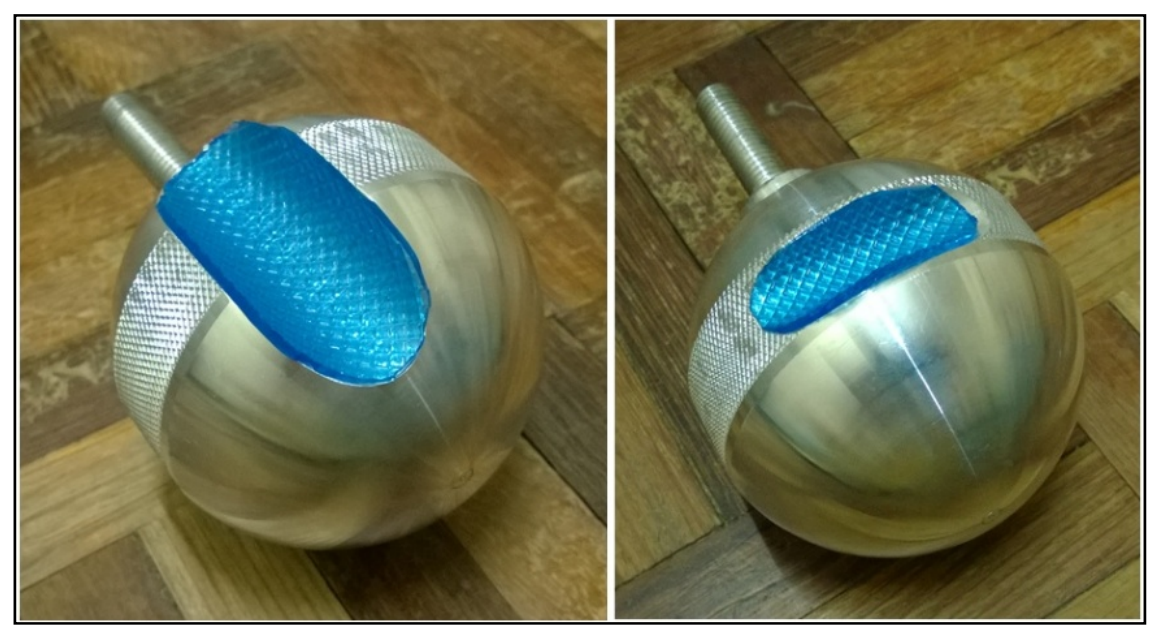

(a)

(b)

Figure 2. Ergonomic Knob Design (a) Groove made for the Thumb (b) Groove made for the Index Finger

\section{Methodology}

The extent of improvement in the ergonomic knob design is determined based on whether it helps to reduce the pinch force exertion on the knob when used with a lateral pinch. A validation is carried out with the inclusion of 6 male and 6 female participants. Proper informed consent is obtained prior to their participation. Each participant is required to perform the knob turning exercise in both clockwise and counterclockwise directions on both of the milling machine knob replica and the ergonomic knob.

The two different knobs are attached on the same wooden stand with a spring loaded mounting as illustrated in Figure 3 to provide a fair comparison. The spring loaded mounting provides a turning resistance in order to simulate the actual equipment's mechanism. Finger cot sensors are used in this validation to gather the pinch force data from the fingers while the participant is turning the knob using the lateral pinch technique.

The working positions of the participant while performing the knob turning operation involve a seated position with a straightened arm. These positions are fixed variables during the validation.

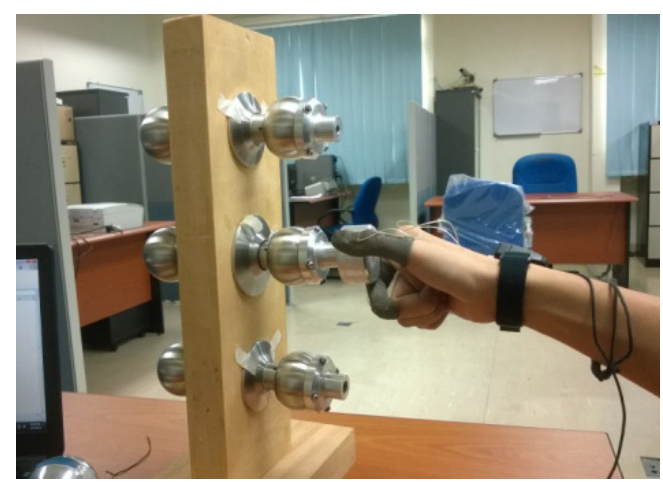

(a)

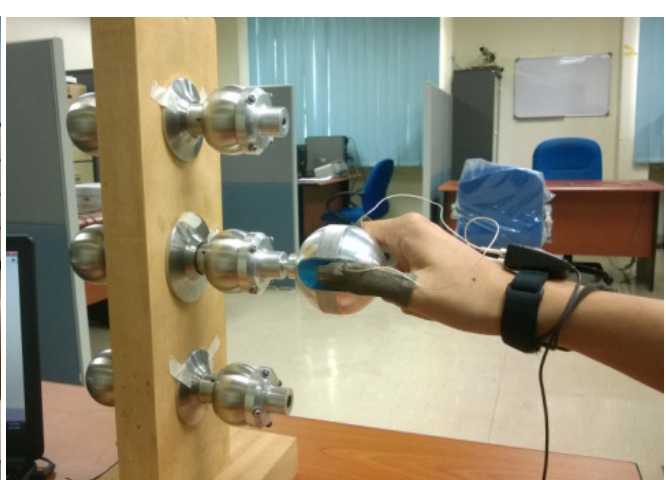

(b)

Figure 3. (a) Milling Machine Knob Replica (b) Ergonomic Knob

\section{Results and Discussion}

Table 1 shows the percentage of change between the ergonomic knob and the milling machine knob replica. The replica of the milling machine control knob, as shown in Figure 1 (b), is covered with straight knurls and the diameter is made to be $51 \mathrm{~mm}$. The improvement of the ergonomic knob over the control knob replica is considerable since much lower pinch forces are required to turn the ergonomic knob as compared to the milling machine knob replica. The improvement is as substantial as $72.42 \%$ in average for the male participants and 
$55.41 \%$ in average for the female participants.

Table 1. Percentage of Change between the Ergonomic Knob Design and the Milling Machine Knob Replica

\begin{tabular}{|c|c|c|c|c|c|c|c|}
\hline \multirow[b]{2}{*}{$\begin{array}{l}\text { Subject } \\
\text { No. }\end{array}$} & \multirow[b]{2}{*}{$\begin{array}{c}\text { Torque } \\
\text { Direction }\end{array}$} & \multicolumn{2}{|c|}{ Male } & \multirow[b]{2}{*}{$\begin{array}{c}\text { Percentage } \\
(\%)\end{array}$} & \multicolumn{2}{|c|}{ Female } & \multirow[b]{2}{*}{$\begin{array}{c}\text { Percentage } \\
(\%)\end{array}$} \\
\hline & & $\begin{array}{l}\text { Ergonomic } \\
\text { Knob (N) }\end{array}$ & $\begin{array}{l}\text { Knob } \\
\text { Replica } \\
\text { (N) }\end{array}$ & & $\begin{array}{l}\text { Ergonomic } \\
\text { Knob (N) }\end{array}$ & $\begin{array}{l}\text { Knob } \\
\text { Replica } \\
(\mathrm{N})\end{array}$ & \\
\hline \multirow{2}{*}{1} & $\mathrm{CW}$ & 1.640 & 14.550 & 88.73 & 1.410 & 7.240 & 80.52 \\
\hline & $\mathrm{CCW}$ & 1.670 & 15.940 & 89.52 & 2.230 & 7.520 & 70.35 \\
\hline \multirow{2}{*}{2} & CW & 0.800 & 2.270 & 64.76 & 1.490 & 2.790 & 46.59 \\
\hline & $\mathrm{CCW}$ & 1.133 & 2.730 & 58.50 & 2.370 & 3.090 & 23.30 \\
\hline \multirow{2}{*}{3} & $\mathrm{CW}$ & 0.913 & 4.310 & 78.82 & 2.860 & 4.610 & 37.96 \\
\hline & $\mathrm{CCW}$ & 1.257 & 5.320 & 76.37 & 3.590 & 9.720 & 63.07 \\
\hline \multirow{2}{*}{4} & $\mathrm{CW}$ & 1.000 & 3.570 & 71.99 & 1.170 & 4.410 & 73.47 \\
\hline & $\mathrm{CCW}$ & 1.200 & 11.770 & 89.80 & 1.810 & 8.270 & 78.11 \\
\hline \multirow{2}{*}{5} & $\mathrm{CW}$ & 1.173 & 1.870 & 37.27 & 3.160 & 6.530 & 51.61 \\
\hline & $\mathrm{CCW}$ & 2.137 & 5.960 & 64.14 & 3.740 & 5.230 & 28.49 \\
\hline \multirow{3}{*}{6} & CW & 1.173 & 4.710 & 75.10 & 1.270 & 3.270 & 61.16 \\
\hline & $\mathrm{CCW}$ & 2.067 & 7.970 & 74.07 & 2.170 & 4.370 & 50.34 \\
\hline & \multicolumn{2}{|c|}{ Average } & & 72.42 & \multicolumn{2}{|c|}{ Average } & 55.41 \\
\hline
\end{tabular}

Note. CW means clockwise while CCW means counterclockwise.

One of the factors that facilitated the ergonomics of this new knob design is the ergonomic shape of the knob (sphere shape). According to Stevenson et al. (2000), spherical shapes provide more comfort with a less strenuous grip on the user's wrist. Another ergonomic feature that aided the pinch efforts of the users is the inclusion of the knurls. These knurls allow higher frictional force to be generated on the surface during the pinch actvity (Imrhan \& Jenkins, 1999).

The groove designs in the knob accommodated the thumb and lateral aspect of the index finger allowed the rotation of the knob in a counterclockwise direction to be less arduous compared to rotating the knob in a clockwise direction. This is because turning the knob in a counterclockwise direction requires a higher amount of effort compared to turning it in a clockwise direction (Armstrong, AshtonMiller, \& Chaffin, 2007; Ng et al., 2014b; Seo et al., 2008).

Another ergonomic aspect that led to the improvement of the knob design includes the increased tactile sensation via the rubbery materials on the groove, which facilitates the pinch force applied on the knob. Studies concur that the efficiency of a grip can be enhanced with a surface that has a higher coefficient of friction (COF) (Seo et al., 2011; Tsaousidis \& Freivalds, 1998). On the whole, the validation has proven that this new ergonomic knob design is indeed viable as a milling machine control knob.

\section{Conclusion}

The ergonomic knob design is confirmed to offer a substantial amount of improvement compared to the milling machine knob replica, primarily when it comes to pinch force reduction. All the added improvement features such as grooves, rubbery materials as well as the overall diameter are the contributing ergonomics factors in this validation, which is relevant to the findings of previous researchers. The results can be used as a basis to develop design guidelines that can potentially improve other product designs that require different knob design parameters.

One of the limitations in this study is in the material used to prototype the knob, which was aluminium. Since a lot of control knobs are made from different materials such as plastic (polymer) and mild steel, the fabrication of the knobs with these materials can be attempted for future studies. This can help improve the validation to be relevant for other types of applications which are beyond the scope of milling machine controls.

\section{Acknowledgements}

This research was supported by the Fundamental Research Grant Scheme (Ref No.: MMU/RMC-PL/AL/FRGS/2013/006) from the Malaysian Ministry of Education. The data presented, statements made and views expressed are solely the responsibility of the authors. 


\section{References}

Armstrong, T. J., Ashton-Miller, J. A., \& Chaffin, D. B. (2007). The Effect of Torque Direction and Cylindrical Handle Diameter on the Coupling between the Hand and a Cylindrical Handle. Journal of Biomechanics, 40(14), 3236-3243. http://dx.doi.org/10.1016/j.jbiomech.2007.04.023

Campbell, S. C., Nolan, P. F., Wharton, R. K., \& Train, A. W. (2000). Measurement of Forces Exerted in the Manual Handling of Small Cylindrical Objects. International Journal of Industrial Ergonomics, 25(4), 349-358. http://dx.doi.org/10.1016/S0169-8141(99)00023-2

Chakrabarti, D. (1997). Indian Anthropometric Dimensions for Ergonomic Design Practice. Ahmedabad, India: National Institute of Design.

Deros, B. M., Yusuff, R. M., Daruis, D. D. I., Mohamad, D., \& Yusoff, A. R. (2013). Anthropometric Research in Malaysia: National Institute of Occupational Safety and Health (NIOSH), Malaysia.

Eksioglu, M., Fernandez, J. E., \& Twomey, J. M. (1996). Predicting Peak Pinch Strength: Artificial Neural Networks Vs. Regression. International Journal of Industrial Ergonomics, 18(5-6), 431-441. http://dx.doi.org/10.1016/0169-8141(95)00106-9

Engel, A. K. J., Enders, L. R., Keenan, K. G., \& Seo, N. J. (2010). Grip Surface Friction Affects Maximum Tip Pinch Force. Paper presented at the The 34th Annual Meeting of the American Society of Biomechanics, Rhode Island, USA. Retrieved from http://bit.ly/1FTnSbk

Fathallah, E. A., Kroemer, K. H. E., \& Waldron, R. L. (1991). A New Finger Strength (Pinch) Gauge. $\begin{array}{lllll}\text { International Journal of Industrial } & \text { Ergonmics, } & 7(1), & \text { 71-72. }\end{array}$ http://dx.doi.org/10.1016/0169-8141(91)90060-Y

Imrhan, S. N., \& Jenkins, G. D. (1999). Flexion-Extension Hand Torque Strengths: Applications in Maintenance Tasks. International Journal of Industrial Ergonomics, 23(4), 359-371. http://dx.doi.org/10.1016/S0169-8141(98)00052-3

Karmegam, K., Sapuan, S. M., Ismail, M. Y., Ismail, N., Bahri, M. T. S., Shuib, S., ...Hanapi, M. J. (2011). Anthropometric Study among Adults of Different Ethnicity in Malaysia. International Journal of the Physical Sciences, 6(4), 777-788. http://dx.doi.org/10.5897/IJPS10.310

Kleiss, J. A. (2008). Sensory Quality Evaluation of Clothes Washing Machine Selector Knobs. Paper presented at the Proceedings of the Human Factors and Ergonomics Society 52nd Annual Meeting, Benton Harbor, Michigan, USA. Retrieved from http://bit.ly/1Ko3Yag

Ng, P. K., \& Saptari, A. (2014). A Review of Shape and Size Considerations in Pinch Grips. Theoretical Issues in Ergonomics Science, 3(4), 305-317. http://dx.doi.org/10.1080/1463922X.2012.729619

Ng, P. K., Bee, M. C., Boon, Q. H., Chai, K. X., Leh, S. L., \& Jee, K. S. (2014a). Pinch Techniques and Their Effects on Pinch Effort: A Pilot Study. Applied Mechanics and Materials, 465-466(11), 1165-1169. http://dx.doi.org/10.4028/www.scientific.net/AMM.465-466.1165

Ng, P. K., Saptari, A., Boon, Q. H., Bee, M. C., Chai, K. X., \& Leh, S. L. (2014b). Pinch Effort Variations with Torque, Shape, Size, Sensation and Technique. Journal of Applied Sciences, 14(5), 401-414. http://dx.doi.org/10.3923/jas.2014.401.414

Ran, L., Zhang, X., Chao, C., Liu, T., \& Dong, T. (2009). Anthropometric Measurement of the Hands of Chinese Children. Paper presented at the Second International Conference, ICDHM 2009, San Diego, CA, USA. Retrieved from http://bit.ly/1YmY8j4

Schutte, M., \& Schuder, D. (1997). Case Study: Investigation into the Subjective Strain at Two Differently Designed Automobile Assembly Workplaces. International Journal of Industrial Ergonomics, 20(5), 413-422. http://dx.doi.org/10.1016/S0169-8141(96)00091-1

Seo, N. J., Armstrong, T. J., Chaffin, D. B., \& Ashton-Miller, J. A. (2008). Inward Torque and High-Friction Handles Can Reduce Required Muscle Efforts for Torque Generation. Human Factors: The Journal of the Human Factors and Ergonomics Society, 50(1), 37-48. http://dx.doi.org/10.1518/001872008X250610

Seo, N. J., Shim, J. K., Engel, A. K., \& Enders, L. R. (2011). Grip Surface Affects Maximum Pinch Force. Human Factors: The Journal of the Human Factors and Ergonomics Society, 53(6), 740-748. http://dx.doi.org/10.1177/0018720811420256

Stevenson, M. G., Coleman, N., Long, A. F., \& Williamson, A. M. (2000). Assessment, Re-Design and 
Evaluation of Changes to the Driver's Cab in a Suburban Electric Train. Applied Ergonomics, 31(5), 499-506. http://dx.doi.org/10.1016/S0003-6870(00)00014-4

Tan, Y. H., Ng, P. K., Saptari, A., \& Jee, K. S. (2014). Effects of Knob Choices on Working Posture Choices in Manufacturing Firms. Paper presented at the International Conference on Automotive Innovation and Green Energy Vehicle, Kuantan, Pahang. Retrieved from http://bit.ly/1KmqthX

Tan, Y. H., Ng, P. K., Saptari, A., \& Jee, K. S. (2015a). Influences of Body Position Selections on Knob Selections in Malaysian Manufacturing Industries. Applied Mechanics and Materials, 761, 683-687. http://dx.doi.org/10.4028/www.scientific.net/AMM.761.683

Tan, Y. H., Ng, P. K., Saptari, A., \& Jee, K. S. (2015b). Roles of Pinch Grips in Different Knob Selections among Malaysian Manufacturing Workers. Applied Mechanics and Materials, 761, 688-692. http://dx.doi.org/10.4028/www.scientific.net/AMM.761.688

Tsaousidis, N., \& Freivalds, A. (1998). Effects of Gloves on Maximum Force and the Rate of Force Development in Pinch, Wrist Flexion and Grip. International Journal of Industrial Ergonomics, 21(5), 353-360. http://dx.doi.org/10.1016/S0169-8141(96)00086-8

Woodson, W., Tillman, P., \& Tillman, B. (1992). Human Factors Design Handbook (2nd ed.). New York, USA: McGraw-Hill Professional Publishing.

\section{Copyrights}

Copyright for this article is retained by the author(s), with first publication rights granted to the journal.

This is an open-access article distributed under the terms and conditions of the Creative Commons Attribution license (http://creativecommons.org/licenses/by/3.0/). 